\title{
Gender-based Failure to Infer Implicatures from Pre-TOEFL Listening
}

\author{
Arifuddin Hasan \\ Universitas Mataram Indonesia \\ arifpgn@yahoo.com \\ Susanto Susanto \\ Universitas Negeri Surabaya Indonesia \\ susantoniki@yahoo.com
}

Accepted: October 08, 2012 Published: November 13, 2012

Doi:10.5296/ijld.v2i6.2681

URL: http://dx.doi.org/10.5296/ijld.v2i6.2681

\begin{abstract}
Inferring conversational implicatures could be difficult for foreign language learners. Some studies show that English proficiency of Indonesian English students, teachers and lecturers are low. Unfortunately, none of the studies dealt with factors which determine the learners' failures to interpret each type of implicature questions on the basis of gender. The present study aimed at exploring types of implicature question of aural short conversations in Pre-TOEFL failed to be answered correctly and their causes experienced by a) males $b)$ females students of EEPUM. Data were collected through Part A Pre-TOEFL test, Inventory of Determining Factors of Failure, Interview Protocol, Recording and Note-taking and analysed with a cyclical qualitative analysis on the basis of Brown \& Yules's theory, Anderson's model and Goh's five factors affecting listening. Types of implicature questions failed to be answered correctly and their determining factors are shown.
\end{abstract}

Key words: Inferring, Implicature, Proficiency, Gender, Failure.

\section{Introduction}

Inferring conversational implicatures could be difficult for foreign language learners. Implicature understanding determines EFL learners' proficiency. English language proficiency of higher education students is low.

Table 1. TOEFL Scores of Three English-related Departments

\begin{tabular}{|c|c|c|c|}
\hline \multirow[t]{2}{*}{ Department } & \multicolumn{2}{|c|}{ TOEFL Score } & \multirow[t]{2}{*}{ Gain } \\
\hline & First Semester & Last Semester & \\
\hline English Language Education & 405 & 519 & 114 \\
\hline English Literature & 424 & 566 & 142 \\
\hline
\end{tabular}




\begin{tabular}{cccc}
\hline English for Business & 406 & 522 & 125 \\
\hline
\end{tabular}

Many English language teachers and even some lecturers showed 'insufficient' English proficiency. Saukah (2000) found that the average TOEFL scores of English language lecturers in Indonesia is only 393, far lower than those of the third year Senior High School students, 435. Arifuddin and Sujana (2003) found that the average English proficiency of the students of English Education Program University of Mataram (henceforth EEPUM), measured with TOEFL, is low, 437, lower intermediate level, far lower than the minimum standard TOEFL score of 500 required for graduation. Listening section score is 462. The researcher assumes that this could be due to low ability in inferring implicatures.

Here are some inferential and pragmatic studies, and some related to gender, for example, Matsuoka's (2009) and Hassani et al. (2011). However, none of the studies dealt with the factors which determine the learners's failures to interpret each type of implicature-inferring questions on the basis of gender. Theoretically, there is a difference ability in pragmatic comprehension between male and female students. To make sure, on November 11, 2011, the researcher conducted a 'preliminary study' on the difference of implicature comprehension of aural short conversation in Paper-based Pre-TOEFL(henceforth PBPT) between male and female students of EEPUM. It shows that male and female students show different level of implicature comprehension. Female's comprehension is better than male's. The majority of the students failed to infer implicatures from short conversations in PBPT. Therefore, it is important to conduct an exploratory study on the determinants of failure to infer implicature that the 'senior' learners experienced.

The present study aimed at exploring: a) the types of implicature-inferring question of aural short conversations in Pre-TOEFL commonly failed to be answered correctly by males and by females b) Common factors believed to determine the failure to infer implicature and their causes based on gender.

Theoretically, the present sudy provides more detailed factors determining the learners failures to infer the implicature from aural short conversations based on gender potentially useful for developing or refining Brown and Yule's (1983) theory. Practically, it will be useful for: a) TOEFL Preparation or English Language Training organised by Language Centres ; b) School; c) TOEFL Books Publishers; d) ETS; and e. Researchers.

\section{Method} study.

As a qualitative study, below is the design and procedures followed in the present 


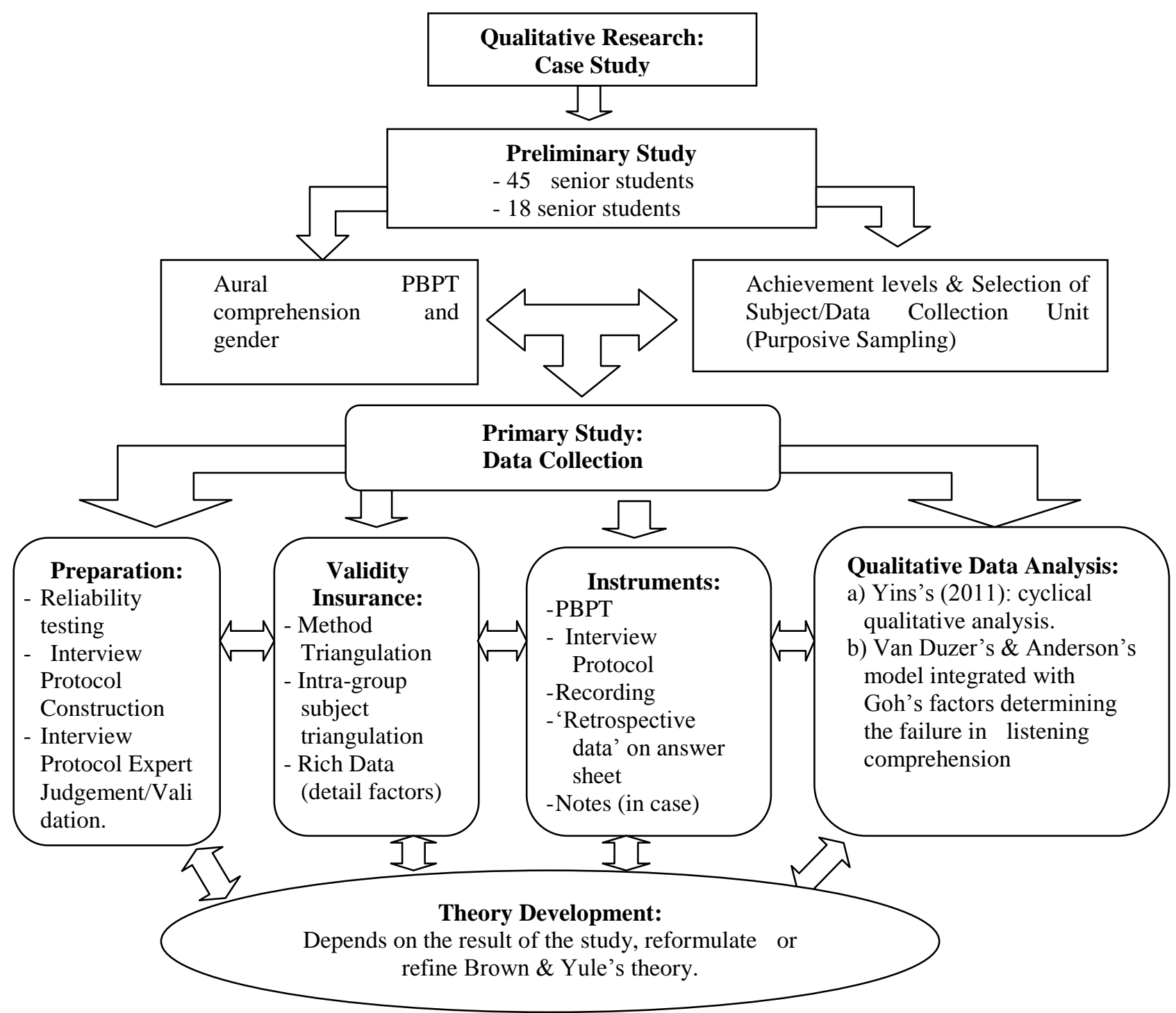

\subsection{Participants}

Six subjects chosen purposivley from 45 students of semester VI (or above) of EEPUM, with the balanced number for each sex. The subjects were selected using purposive sampling based on the result of preliminary study using the aural PBPT test administered prior to the primary study. The criteria of the subjects: 1) Students of semester VI or above 2) Never attended TOEFL training and 3) Never did the test used as the instrument of this study. Their roles will be the 'bystander' inferers of the speaker's and hearer's utterances and the sources of data dealing with difficulties in recognising implicatures within various types of implicature question and common difficulties in comprehending aural Pre-TOEFL listening tests.

\subsection{Instruments}

Data were collected with: 1) Test, 2) Inventory of Determinants of Failure, 3) Interview Protocol; 4 Recording; and 5) Researcher. 


\subsection{Procedure}

Data were analysed with an interactive, cyclical qualitative analysis adapted from Yin (2011:178). Data about types of implicature questions were identified based on Miller's (2001) typology. Data about factors which cause failure in deriving implicatures from conversations and determining factors for each stage of Anderson's model will be managed and analysed based on: a) Brown \& Yule's 'theory regarding with factors determining success in listening comprehension' and and b) Anderson's 'model of listening comprehension stages' integrated with Goh's 'five characteristics of factors affecting listening comprehension' through the following procedures: 1. identifying and selecting: a) the types of implicature questions answered incorrectly based on gender and b) the types and causes of failure in listening comprehension for each type of implicature question based on gender; 2. codifying the data about types and causes of failure to infer implicatures related to gender); 3. disassembling, list the types of implicature questions answered incorrectly; 4. reassembling (i.e. sythesising and reducing by integrating and sythesising factors believed to determine their failure); 5. discussing and interpreting - disussing the findings; and 6. concluding and verifying.

\section{Result and Discussion}

\subsection{Types of Implicature-inferring Qustions which Males Failed to Answer and the Determining Factors of Failure}

Based on the identification of implicature-inferring questions contained in the test as the instrument of the present study, there appear only six types of implicature-inferring Questions found in the test used in the present study, namely: a) Meaning/intent; b) Inference/implication/conclusion; c) Deictic involving situation or setting (location or time); d) Presupposition/assumption/attitude/tone; e) Reference/identification; and f) Predictable action. However, the implicature-inferring questions failed to be answered correctly by male subjects include: a) Meaning/intent; b) Inference/implication/conclusion; c) Deictic involving situation or setting; d) Presupposition/assumption/attitude/tone; and e) Reference/identification.

\subsubsection{Meaning/intent Question}

This type of implicature-inferring question is dominantly failed to be answered correctly by male subjects. Those are items 1, 4, 8, 9, 10, 11, 12, 13, 14, 18, 19, 22, 25 and 28 , and as a sample, only one test item is presented for each type of question. For systematicity, data number and item number are put in pairs, (Data number)(Test item number).
(1)(4) Man : On Monday, Betty starts with the tool company.
Woman : I am surprised she charged her mind about not taking that job.

Narrator : What does the woman mean?

The determining factor of failure to answer the test item above sentence complexity and speech act/language functions understanding and accent.

The subjects believed that their failure to answer this item incorrectly is due the complexity of the sentences in those conversations above, and listening to such types of sentence is confusing. One could also propose that the longer items would be more difficult, as exminees would have more language to retain and understand. Several TOEFL researchers have hypothesised that syntactic complexity affects listening comprehension such that the more complex the syntax is in a text, the more difficult it is to comprehend (Kostin 2004:3). So, the length or complexity of sentences may lead to either difficulty or ease for the listeners. 
The 'diversity' Englishes also generate diverse cultural content and linguistic distinctions, for instance, spelling, pronunciation, intonations, accent, etc. could be difficult even for the native speakers of different Englishes. Accent, pronunciation and colloquial expressions found to be the major obstacles in the development of listening skills among students as also indicated by Butt et al. (2010) study. Why is sound discrimination or perception is crucial in listening comprehension? Although they have taken Discourse Analysis and Cross-cultural Understanding, listening to western music and movies, even communicate with native speakers in the tourist objects they still find difficulties in perceiving and understanding speech acts or language functions. This is relevant with Goh's five most common factors - vocabulary, prior knowledge, speech rate, type of input and speaker's accent -- that influence the students' listening comprehension, vocabulary mastery occupies the most common factor.

In reality, many learners of English encounter more difficulties in listening which could be due to lack of understanding of the pragmatic messages as an aspect of socio-cultural and socio-linguistic understanding implied in the aural texts or conversations. It has been widely accepted that high proficiency L2 learners are generally more competent in interpreting implied meaning of utterances than low proficiency L2 learners (Lee 2010).

The failure is also caused by the speech rate/speed delivery. The subjects are not accustomed to interpreting implicature or speaker meaning from 'speedy' conversation. Lack of understanding of underlying cultural value within the conversation also affects understanding. Understanding a foreign language is controlled by particular cultural experiences (Gilakjani and Ahmadi 2011). Every time we speak we perform a cultural act/values, so that it is necessary that cultural knowledge be involved in language teaching/learning. Consequently, every conversation in PBPT contains at least a cultural value, but it seems questionable related to the fact that in short conversation of Listening Part A TOEFL, three classifications were defined regarding cultural vocabulary: Type A (No cultural vocabulary), Type B (Cultural vocabulary, the understanding of which is not critical to answering correctly) and Type $\mathrm{C}$ (Cultural vocabulary, the understanding of which is critical to answering correctly). The inclusion of pragmatic constructs such as idioms and culturally-specific vocabulary decreases comprehension, and L2 listeners have a harder time understanding passage that contain culturally specific expressions, words and idioms (Bloomfield et al. 2011). Accent, pronunciation and colloquial expressions were the major obstacles in the development of listening skills among students (Butt et al. 2010).

Hypothetically, listening skills could be acquired through exposure, not really taught (Alagozlu and Buyukozturk 2009). In other words, for foreign language learners, lack of exposure to the foreign language environment inhibits the improvement of learners pragmatic competence, but many scholars also suggest that pragmatic competence be integrated in foreign language teaching (Chen 2009). Unfortunately, although male subjects have more opportunities, or exposure, to interact with native speakers in the real situations, it has not directly improved their pragmatic ability.

\subsubsection{Inference/implication/conclusion question}

For this type of implicature-inferring question, the difficult items are 2, 3, 6,

$12,15,16,17$ and 20.

(9)(2) Man : I'd like to take Math three-o-five (305) this semester.

Woman : To register for the course, students must have the instructor's 


\section{permission.}

Narrator : What does the woman imply?

Limited understanding of speech acts/language functions also makes the test item failed to be inferred accurately. It is hypothesised that listening skills could be acquired through exposure (Alagozlu and Buyukozturk 2009). For foreign language learners, lack of exposure to the foreign language environment inhibits the improvement of learners pragmatic competence, but many scholars also suggest that pragmatic competence be integrated in foreign language teaching (Chen 2009). Unfortunately, although male subjects have more opportunities, or exposure, to interact with native speakers in the real situations, it has not directly improved their pragmatic ability.

The failure to infer implicature from this conversation results from inability to recognise unknown words and chunking. The cause of failure is also related to pronunciation, setting and implicitness. The unfamilarity with the phonological variables and limited exposure to the target language may affect item difficulty of aural conversation, for instance that of PBT (Kostin 2004:3).

3.1.3 Deictic questions involving situation, setting (location or time)

The items failed to be answered incorrectly are 23, 24 and 26, and only item 23 is presented. The causes of failure include understanding of speech acts, context, implicitness and rhetoric.

(16)(23) Man

: How big a tip should we leave?

Woman : Fifteen percent would be two dollars.

Narrator : Where is the conversation taking place?

The cause of failure to answer these items correctly is speech act/language function understanding and implicitness. There are some difficulties, two of which are the different sound and intonation between Indonesian language and English. The causes of the inability is unfamiliarity with context and rare interaction with native speakers or exposure.

3.1.4 Presupposition/assumption/attitude/tone question

The items of this type of implicature-inferring question failed to be answered correctly are 7, 27 and 30, and only item 7 is shown.

(19)(7) Woman : We had a great time. And so many people came!

Man : It was very nice of George to give me a party.

Narrator : What does the man say about George?

The failure to answer correctly those items relates to speech acts/language functions understanding, cultural values, sentence complexity, discourse markers, gender and implicitness. Speech act/language function understanding contributes to the ability to infer this conversation. Low proficiency L2 learners are generally more less competent in interpreting implied meaning than high proficiency L2 learners (Lee 2010). For foreign language learners, lack of exposure to the foreign language environment inhibits the improvement of learners pragmatic competence, but it is believed that pragmatic competence be integrated in foreign language teaching/classroom.

3.1.5 Reference/identification question

The difficult item for this type of implicature-inferring question is 27.

(22)(27) Woman : Your super-unleaded grade is pretty expensive.

Man : I don't think it's more expensive than at other places.

Narrator : What is the man's occupation?

The failure of answering this test item results from lack of speech acts/language functions understanding, context, implicitness and concreteness. The difficulty in 
understanding language functions or speech acts in short conversations also results from the diversity of English in the world, limited vocabulary, unfamiliarity with intonation underlying certain speaker meaning or implicature, unfamiliarity with intonation, pronunciation or accent which may determine the speaker meaning or implicature. Interlocutors should have sufficient inferential ability, and such an ability should be sharpened because it is a complex skill. Inferential comprehension requires more cognitively complex skills compared to literal comprehension. Therefore, practice is needed to improve inferential ability. By so doing, the interlocutors would not face misunderstanding during an interactive communication.

\subsection{Types of Implicature-inferring Questions which Females Failed to Answer Correctly and Determining Factors of Failure}

Based on the ranks of the difficult implicature question, the types of implicature-inferring questions failed to be answered correctly by females are a) Meaning/intent, b) Inference/implication/conclusion, c) Deictic questions involving situation and setting, d) Presupposition/assumption/tone, e) Reference/Identification and f) Predictable action.

3.2.1 Meaning/intent question

The items of this type of implicature-inferring question failed to be answered correctly are $1,4,8,9,11,14,18,19,21,22,25$ and 28 , and only item 4 is shown.
(24)(4) Man : On Monday, Betty starts with the tool company.
Woman : I am surprised she charged her mind about not taking that job.
Narrator : What does the woman mean?

In order that communication intention manifested successfully, the hearer tries to understand the motives, purposes, topics or 'meanings', including irony, behind the speaker's utterances. Substantially, speech act is the whole communicative situation, including the context or situation of utterance and paralinguistic features, for instance, intonation, pronunciation, etc. which may contribute to the implicatures of the verbal interaction. Everyone speaks differently and uses forms of connected speech in different ways.

In addition, regional or national accent, chunking and discourse markers also cause the failure to answer correctly test item. The subjects admitted that they did not know many accents and rarely listened and use of reduced forms (or chunking). One function of a discourse marker is to make the relation or the structure of sub-ideas or sentences coherent or to signal the rhetorical structure of a passage or discourse.

An indirect meaning asked with question,"What does the man/woman mean?" is hypothesised to be more difficult than an more direct one,"what does the man say about the computer program?" Indirect passages which include more implied information can also be more difficult for L2 learners to comprehend or interpret. Lower-proficiency listeners may have difficulty when a passage contains a large number of implicatures or other indirect forms of communication (Bloomfield et al. 2011:37). A text with an implicit proposition requires more complex processing than one with the proposition is explicit.

3.2.2 Inference/implication/conclusion question

The items failed to be answered correctly of this type of question are 2, 3,

$5,6,16,17,20$ and 0nly item 5 is presented. 
(34)(5) Woman : Today, I had a lot to do, with all the little things to take care of.

Man : You dropped off my jacket at the cleaner's, didn't you?

Narrator : What does the man want to know?

The failure to infer implicature is low understanding of the implicit cultural values and their indicators. They still lack recognition of cultural value indicators. They don't understand cultural values implied in the conversation, never heard them and rarely listened to movie. The difference of cultural values between the subject's and English native speakers' and the unfamiliarity with politeness or cultural value indicators makes implicature difficult to infer.

3.2.3 Deictic questions

The items of this type of implicature-inferring questions failed to be answered correctly are 23, 24 and 26 and only item 23 is presented. The determining factors of failure include cultural value, speech acts/language functions understanding, context, sentence complexity and rhetoric.

(37)(23) Man : How big a tip should we leave?

Woman : Fifteen percent would be two dollars.

Narrator : Where is the conversation taking place?

Recognising cultural values in conversations is difficult. Native speakers of English have different cultural values from the learners do. They still lack of recognition of politeness indicators which also relate to cultural values.

3.2.4 Presupposition/assumption/attitude/tone question

Items answered incorrectly are 7,17 and 30.

(40)(7) Woman : We had a great time. And so many people came.

Man : It was very nice of George to give me a party.

Narrator : What does the man say about George?

The subjects' failure to infer implicature of this conversation results from unfamiliarity with context and cultural values. The difference of cultural values between the subject's and English native speakers'. According to Butt et al. (2010), colloquial expressions places the top three factors, after accent and pronunciation, which cause problems in listening comprehension among EFL learners.

3.2.5 Reference/identification question

The item failed to be answered correctly is 27 .

(43)(27) Woman : Your super-unleaded grade is pretty expensive.

Man : I don't think it's more expensive than at other places.

Narrator : What is the man's occupation?

Factors affecting the failure to infer this item are sentence complexity and lack of understanding of speech act/language functions understanding. Speech act is difficult due to the presence of irony and unfamiliarity with the context of the conversation. As an indirect speech act, an irony implies a purpose or meaning. An implicature, for insatance, irony, is a special case of situations in which the perceived meaning extends beyond the literal meaning or direct speech act.

3.2.6 Predictable Action Question

The item of this type of question failed to be answered correctly is 29 .

(44)(29) Man : It's time to go home, Karen. Dave and I are on our way to an Italian restaurant on High Street. Would you like to come to 


\author{
dinner with us? \\ Woman : Thanks, but I have the travel report to finish. I need to mail it \\ first thing tomorrow morning. \\ Narrator : What is Karen going to do?
}

This item is incorrectly answered because the subject did not recognise the context. According to her, she didn't understand the context because she was never involved in and exposed to travel business. The exposure in the real situation or context of language use may improve EFL learners language proficiency, including listening skill.

It is found that:

1. Types of implicature questions in aural short conversations of Pre-TOEFL which males failed to answer correctly are: a) Meaning/intent; b) Inference/implication/conclusion; c) Deictic questions involving situation or setting; d) Presupposition/assumption/attitude/tone; and e) Reference/identification.

2. The (five) common factors males believed to determine their failure to infer implicatures from aural short conversation of Pre-TOEFL are: a) speech act/language functions understanding, b) sentence complexity, c) cultural value, d) intonation and stress, e) clarity of speaker's voice, chunking, IDSLC (vocabulary, i.e. idiomatic expressions, slangs, colloquials) and implicitness.

The causes of why males failed to answer correctly are: a) lack of understanding of language functions due to limited socio-cultural and socio-linguistic understanding; b) implicitness and inconcreteness of the speaker meaning; c) lack of exposure to the foreign language environment; d) diversity of English underlying different realisation of intonation, stress, pronunciation/sound or clarity of voice, chunking, accent and speech rate/speed delivery; e) insufficient inferential ability especially when inferring pragmatic meaning of long, complex sentences; f) inability to comprehend the meaning of rhetoric devices or discourse markers; g) failure in detecting the topic, focus, intent or meaning, context and setting; h) inability to recognize unkown words or forgotten vocabulary (idioms/slangs/colloquials); and i) difficulty in interpreting implicatures from speaker with different gender.

3. Types of implicature questions in aural short conversation of Pre-TOEFL which females fail to answer include: a) Meaning/intention, b) Inference/implication/conclusion, c) Deictic involving situation and setting, d) Presupposition/assumption/tone, e) Reference/Identification and f) Predictable action.

4. The (five) common factors that females believed to determine their failure to infer implicatures from aural short conversationsof Pre-TOEFL are: a) cultural value, b) sentence complexity, c) speech act/language function understanding, d) context, and e) implicitness, discourse markers/rhetoric, accent and chunking.

The causes why females failed to infer implicatures from aural short conversations based on ranks are: a) lack of speech act/language function understanding makes the topic of complex sentences in an aural conversation difficult to recognise because it is tricky and distracting, b) lack of recognition of cultural values, i.e. politeness indicators and the difference of cultural values between the subjects' and English native speakers', c) the 'implicitness' of speaker meaning from the speech act words, d) unfamiliarity with context due to lack of exposure, e) inability to grasp the underlying meaning in intonation which makes liteners failed to infer the implied irony, f) unfamiliarity with the diverse accents, g) difficult in segmenting continuous sounds and chunking, h) It takes long time to infer long, complex sentences, and i) absence of discourse markers or rhetoric device(s) or inaccuracy in inferring implicatures from conversations containing micro-discourse markers. 
5. Based on the entire determining factors found in the present study, males faced more diverse determining factors of failure than females did. Compared with Brown and Yule's theory proposing four determining factors of success or failure in listening comprehension (the listener, the speaker, content, and visual support), the order and scope of the determining factors of failure to infer implicature obtained from the present study are a little bit different from his proposed theory. The new orders or scopes are as follows:
a. Males: Content, speaker, and listener
b. Females: Content and speaker or listener.

\section{Acknowledgment}

We are so greatful to the Higher Education Directorate Department of National Education Republic of Indonesia and University of Mataram sponsoring this research.

\section{References}

Alagozlu, N. and S. Buyukozturk. (2009). 'Aural pragmatic comprehension.' Novitas-ROYAL 3/2: 83-92.

Arifuddin and Sujana. (2003). 'Kecakapan berbahasa Inggris mahasiswa senior bahasa Inggris FKIP Universitas Mataram.' Hasil Penelitian yang tidak dipublikasikan. Mataram: Lemlit Universitas Mataram.

Bloomfield, A., S.C. Wayland, E. Rhoades, A. Blodgett, J. Linck, and S. Ross. (2011). 'What makes listening difficult? Factors affecting second language listening comprehension.' Maryland: ${ }^{\circ}$ UNIVERSITY OF MARYLAND CENTER FOR ADVANCED STUDY OF LANGUAGE. All Rights Reserved February 2011.

Brown, G. and G. Yule. (1983). Teaching the spoken language. Cambridge: Cambridge University Press.

Breland, H., Y-W. Lee, M. Najarian, E. Muraki. (2004). 'Analysis of TOEFL CBT writing prompt difficulty and comparability for different gender groups.' TOEFL Research Reports, Report 76 February 2004. Princeton, NJ: ETS.

Butt, M.M, M.M. Sharif, M. Naseer-ud-Din, I.Hussain, F. Khan, and U. Ayesha. (2010). 'Listening comprehension problems among the students: A case study of three Govt. Boy's higher secondary schools.' European Journal of Social Sciences 18/2.

Chen, Y. (2009). 'Learner perceptions of instruction in L2 Pragmatics.' English Language Teaching Journal 2/4:154-161.

Gharaghani, Z., A.E. Rasekh, A. Dabaghi, and I. Tohidian. (2011). 'Effect of gender on politeness strategies in greetings of native speakers of Persian: English and EFL learners.' Cypriot Journal of Educational Sciences 3:93-117. 
Hassani, R., M.Mardani and H.V. Dastjerdi. (2011). 'A Comparative Study of Refusals: Gender Distinction and Social Status in Focus.' The International Journal - Language Society and Culture Issue 32:34-46.

Kostin, I. (2004). 'Exploring item characteristics that ar related to the difficulty of TOEFL dialogue items.' Research Report RR-79 July 2004. OETS TOEFL.

Lee, C. (2010). 'An exploratory study on the interlanguage pragmatic comprehension of young learners of English.' Pragmatics 20/3:343-373. International Pragmatics Association.

Matsuoka, Y. (2009). 'Possible strategies for listening comprehension: Applying the concepts of conversational implicature and adjacency pairs to understand speaker intention in the TOEFL listening section.' Accent Asia 3/2:27-56.

Miller, G.S. (2001). 'Cracking the TOEFL CBT. Princeton's Review. [Online] Available: http://www.csie.ntu.edu.tw/ b93021/CBTlisteningwz01.pdf. (2 May 2012).

Samian, S.H and H.V. Dastjerdi. (2012). 'The relationship between prior knowledge and EFL leraners' listening comprehension: Cultural knowledge in focus.' Mediterranean Journal of Social Sciences 3/1.

Saukah, A. (2000). 'The English proficiency of the academics of the teacher training and education institutions. Jurnal Ilmu Pendidikan 7/1:67-75. Malang: LPTK and ISPI.

Yin, R.K. (2011). Qualitative research from start to finish. New York \& London: The Guilford Press. 